(1)

CrossMark

\title{
Minimising the environmental impact of inhaled therapies: problems with policy on low carbon inhalers
}

\author{
Duncan Keeley ${ }^{1}$, Jane E. Scullion ${ }^{2}$ and Omar S. Usmani ${ }^{3}$ \\ Affiliations: ${ }^{1}$ Thame, UK. ${ }^{2}$ University Hospitals of Leicester NHS Trust, Leicester, UK. ${ }^{3}$ National Heart and \\ Lung Institute, Imperial College London, London, UK. \\ Correspondence: Omar Usmani, Imperial College London and Royal Brompton Hospital, National Heart and \\ Lung Institute (NHLI), Airways Disease Section, Dovehouse Street, London SW3 6LY, UK. E-mail: o.usmanid
} imperial.ac.uk

@ERSpublications

Uncritical implementation of policy risks deterioration in patient inhaler choice http://bit.ly/2RluJti

Cite this article as: Keeley D, Scullion JE, Usmani OS. Minimising the environmental impact of inhaled therapies: problems with policy on low carbon inhalers. Eur Respir J 2020; 55: 2000048 [https://doi.org/ 10.1183/13993003.00048-2020].

As global citizens, we have a duty to reduce the serious threats posed to planetary well-being and population health by environmental degradation and climate change. These now unquestionable threats to our future are due to human population growth and the resource consumption patterns of the human race. In tandem, as healthcare professionals, we should seek the best possible outcomes of our treatment for our patients and we need to consider equity between different groups of patients. In the speciality of respiratory medicine, the current controversy over how to deal with the role in global warming of the propellants used in pressurised metered dose inhalers (pMDIs) is a very pressing example of how these sometimes conflicting imperatives confront us in our daily practice.

\section{What is the association between inhaler propellants and global warming?}

The 1990s saw major success in global action to avert an environmental threat: the depletion of the ozone layer. This was achieved by ending the production of chlorofluorocarbons (CFCs), the gases used as refrigerants and (in much smaller quantities) as the propellants in pMDIs used to treat asthma and COPD. CFCs were extremely potent global warming agents as well as harmful to the ozone layer. They were replaced by hydrofluoroalkanes (HFAs) which, though harmless to the ozone layer, still have a global warming potential (GWP) more than 1000 times greater than carbon dioxide [1]. With growing concern about global warming in the past couple of decades, there is now a European and worldwide initiative to phase out the production of HFAs, and to find alternative compounds of low GWP [2]. It should however be noted that only a very small proportion of global usage of HFAs is for use in pMDIs: the vast majority is accounted for by refrigeration and air conditioning equipment.

In response to this, the UK is the first European nation that has taken a rather radical step. The UK Government's Environmental Audit Committee (EAC) has set the UK National Health Service (NHS) the challenge of reducing the GWP impact of respiratory treatments by $50 \%$ before 2022 [3]. However, their report has framed this primarily as a directive to reduce the use of pMDIs and increase the use of dry powder inhalers (DPIs). Indeed, there is little consideration to other inhaler options such as soft mist inhalers, newer inhaler devices with low GWP, that receive no mention in the EAC report [4]. 
In the UK, pMDIs account for a higher proportion of inhaler use compared with other European countries [5]. HFAs in pMDIs account for 3\% of the carbon footprint of the NHS, which in turn accounts for $3.5 \%$ of the UK carbon footprint [3]. Thus, pMDIs contribute only $0.1 \%$ to the total UK carbon footprint. There are concerns that the EAC edict may have adverse effects on quality of care and patient outcomes.

\section{What are the challenges for quality of care and patient outcomes?}

There is an urgent and pressing need for a broader approach to the problem of the environmental impact of respiratory treatments; notably, involving better overall standards of care and improving healthcare professional and patient training in inhaler technique [6]. An indiscriminate and uncritical switch from pMDIs to DPIs for respiratory treatment will run the risk of patient harm from worse outcomes of treatment. Young children and many elderly people can only be treated effectively with a pMDI and spacer, and it has been shown that in exacerbations of asthma or COPD, a pMDI with a spacer is the most effective route for inhaled treatment $[7,8]$. It is therefore very important to ensure continued access to this treatment method for the self-management of exacerbations. One way of achieving this in patients who are being offered DPIs in lieu of pMDIs for routine treatment is to provide an emergency treatment pack with pMDIs and a spacer for use in exacerbations [9].

Patient preference is important in achieving effective treatment and many patients prefer pMDIs. In a non-industry funded study comparing the same drug given to patients with asthma as either a pMDI or as a DPI, nearly double the number of patients $(\sim 60 \%)$ preferred the pMDI device compared to the DPI $(\sim 35 \%)$ [10]. Evidence on the error rates that patients have using the different inhaler devices in routine daily use is conflicting, with no convincing evidence for the superiority of any one device type over another. Error rates are high with all device types and have not improved over time [11] and there is a lack of consensus on the definition of and impact of inhaler errors on patient outcomes [12]. What is certain is that ignorance of how to teach correct inhaler technique remains widespread amongst healthcare professionals, and spans several generations. The importance of inhaler technique training has been underrated in medical, nursing, pharmacy and physiotherapy undergraduate and postgraduate teaching across three decades [13-15]. The fact that inhaler technique is so poor and has improved so little over time is a major challenge and evidence of a serious failure of care. In this context, asking healthcare professionals to switch their stable patients using pMDIs to DPIs is a cause for concern, and is unlikely to improve health outcomes in itself. This is particularly true if changing inhalers were to be undertaken without careful individual patient discussion and follow-up. Indeed, in an "enforced" government switch in Finland in a time of financial crisis, where stable respiratory patients were switched to lower cost inhalers, increased morbidity and worsening outcomes in patients with asthma and COPD were observed [16]. Governments must beware of unintended adverse effects of their policies on patient outcomes.

\section{What is the relevance of the inhaler device?}

Inhaler device choice and inhaler technique training each have a major impact on patient outcomes. DPIs require the patient to generate the correct inspiratory flows to de-aggregate (break up) the powder in the device and disperse (carry the drug) into the lungs. Each DPI on the market has its own inspiratory flow requirement to activate powder de-aggregation and achieve effective lung delivery, and the difficulty for some patients to achieve adequate inhalation flows from DPIs in real-life is well-documented [17]. In contrast, pMDIs disperse the drug automatically but rely on the patient to coordinate actuation of the device with inhalation [18]. Difficulty in coordination may be largely overcome by using a spacer or valve-holding chamber, which substantially increases the effectiveness of treatment [19].

Asthma mortality is higher in the UK than in many other European countries [20]. There is, however, no scientific evidence to suggest a connection between higher rates of pMDI use in the UK and higher asthma mortality. Rather, the National Review of Asthma Deaths in the UK suggested inappropriate prescribing in patients with asthma, with suboptimal use of inhaled corticosteroid and overuse of short-acting reliever medication [21]. A more important difference between the UK and neighbouring nations of comparable economic development is our relative under-investment in health services, and the shortness of consultation times in primary care where the vast majority of the care and self-management training of patients with asthma and COPD takes place. The past decade has seen a substantial increase in primary care workload in the UK without commensurate increase in resources.

\section{What about the cost?}

Considerations of the cost of treatment are important in high income countries, and even more so in lowand middle-income countries. There is a huge toll of avoidable morbidity and mortality due to the unaffordability of basic asthma medicines in low- and middle-income countries [22]. In many cases, pMDIs are significantly less costly than DPIs and a shift towards greater use of DPIs could cause a 
substantial increase in healthcare drug costs [23], unless doctors are rigorous in choosing the lowest cost alternatives when switching. However, the potential detrimental consequences on patient outcomes based on low-cost inhaler alternatives have been described earlier [16].

A case has been made for including the environmental impact of treatments in assessing their costs. But if we are to make any impact on the overall problem of global warming, the same approach should be taken to how we assess and pay the costs of everything else we do: how we travel, how we heat our houses, what food we eat, which account for $99.9 \%$ of our carbon footprint. We all recognise and acknowledge that global warming is a highly emotive topic. Information for patients on the environmental impact of respiratory treatments must be put in context, and delivered by healthcare professionals in an evidence-based manner. Patients' clinical interests must be at the core of any consultation to change inhaler device, particularly when they are stable on their established device, and healthcare professionals themselves must have the knowledge and skills to optimise the choice and use of inhalers.

\section{What is the way forward?}

Addressing the problem of global warming is mainly about promoting major individual and global change in patterns of consumption of fossil fuels, travel, and diet. Changes in respiratory care patterns are only a small piece of the jigsaw. Our patients care about the environment and are well disposed to hearing about how to help, but they must not feel picked on.

Plastic waste is itself a major environmental problem, and plastic manufacture and disposal has its own significant carbon footprint. Effective recycling of waste plastic is challenging. We must improve overall care standards, optimise inhaler technique, and maximise recycling. The perfect inhaler on environmental grounds might be a pMDI using a low GWP propellant in a reusable metal canister housed in a simple and reusable plastic case. We must not stifle innovation. Concerted research and development has developed low GWP alternatives (HFA-152a) for use as pMDI propellants [24], which are now incorporated into the clinical development programme of environmentally friendly commercial inhalers for patients that will be available by 2025 [25].

The intervention that would do the most to reduce the overall climate change impact of respiratory treatments, to reduce the waste of resources and to improve patient outcomes, would be to improve our

TABLE 1 Reducing the environmental impact of inhalers in respiratory care

What to do How to do it

Improve asthma control and reduce use of SABA reliever inhalers

Improve COPD control and reduce use of SABA reliever inhalers

Promote effective self-management

Ensure all inhalers are used with correct technique for greater effectiveness

Make optimal use of spacers to increase clinical effectiveness of pMDIs where these are used

Prescribe pMDIs so as to minimise propellant quantity and consider alternative inhaler brands

\section{Ensure patients have a pMDI and spacer emergency treatment pack for self-management of exacerbations, especially if using DPIs for regular treatment \\ Ensure pMDIs are not discarded before they are empty}

Promote inhaler recycling
- Encourage regular preventer treatment by every means possible, empowering patients by helping them understand their condition and how their treatments work

- Ensure that health professionals understand the dose ranges and relative potencies of inhaled corticosteroids

- Smoking cessation, exercise promotion and pulmonary rehabilitation, flu immunisation, regular long acting bronchodilators

- Written personal action plans

- Know how to teach this and do it

- Encourage use of online video tutorials

- Put questions about inhaler technique in the final examinations for all healthcare professionals

- Consider in patient using pMDIs to use spacers to aid inhalation: increases lung deposition and reduces oral deposition of drug

- For example, Salamol inhaler contains half as much propellant as Ventolin inhaler for equivalent dosage, and beclometasone $200 \mu \mathrm{g}$ one puff twice daily uses half as much propellant as beclometasone $100 \mu \mathrm{g}$ two puffs twice daily

- Provide emergency treatment packs with clear simple pictorial instructions for their use

- Teach patients how to recognise correctly when inhalers are empty

- Encourage wider use of dose counters on pMDls

- Encourage local pharmacies to develop and promote use of inhaler recycling schemes to reduce waste of plastic, metal and propellant

SABA: short-acting $\beta$-agonist; pMDI: pressurised metered dose inhaler; DPI: dry powder inhaler. 
overall standards of care for these patients. If we are truly concerned about sustainability and green healthcare, we need to consider not just the issue of propellants and plastic waste, but also the waste and environmental damage caused by poorly managed asthma and COPD. This leads to time off work and school, unnecessary use of unscheduled healthcare and unnecessary trips to hospital and clinics, and a massive and costly waste of inhalers due to incorrect use. These are resources that would be saved if we taught patients more effective self-management; both for routine treatment and for disease exacerbations.

Considering a low GWP inhaler for a stable patient should first and foremost be guided by clinical considerations for the patient, taking care to avoid worsening of their asthma or COPD disease control. This is only one measure among many that we need to take if the problem of the environmental impact of respiratory treatments is to be effectively addressed. The development of alternative low GWP propellants is a key objective. It is vital, both in the UK context and internationally, that patients with asthma and COPD who need them retain access to pMDIs. This may require a temporary exemption for the continued production and use of HFAs for medical purposes just as there was for CFCs in the 1990s, until environmentally friendly inhalers become available commercially [25].

Recycling schemes need to be developed and promoted to reduce the waste from used inhalers. pMDIs can be discarded with a significant proportion of their content unused. This source of waste would be reduced, where health economies can afford this, if it were made a requirement that all pMDIs should be manufactured with dose counters.

Healthcare professionals need to be informed of the wide range of ways in which the environmental impact of respiratory treatments can be reduced while maintaining or improving quality of care (table 1). Unwieldy patient decision aids on inhaler choice that heavily focus on the issue of the choice between DPIs and pMDIs do not help [26]. Healthcare professionals need a shorter, simpler and more practical document advising how to consider environmental issues in respiratory treatment.

We must also remember that, in asthma, a major challenge is to motivate people to take the correct treatment regularly, while in people with COPD feelings of self-blame are common. We must avoid making people with respiratory disease who need or choose pMDIs feel guilty about using their treatment. Our discussions on the issue of climate change need to be framed within the context of the wider political and behavioural changes necessary if the problem is to be meaningfully addressed, and we must not make patients with respiratory disease the only recipients of whatever time we have for raising the important issue of climate change in consultations.

Conflict of interest: D. Keeley has nothing to disclose. J.E. Scullion reports personal fees from AstraZeneca, Boehringer Ingelheim, Chiesi, Napp, Mundipharma, Sandoz, Teva, Roche, Guidelines for nurses, MA healthcare, Orion and MIMS, outside the submitted work. O.S. Usmani reports grants and personal fees from AstraZeneca, Boehringer Ingelheim and Chiesi, grants from GlaxoSmithKline, Prosonix and Edmond Pharma, personal fees from Aerocrine, Napp, Mundipharma, Sandoz, Takeda, Zentiva, Cipla and Pearl Therapeutics, outside the submitted work.

\section{References}

1 Myhre G, Shindell D, Bréon FM, et al. Anthropogenic and natural radiative forcing. In: Stocker TF, Qin, D, Plattner GK, et al., eds. Climate Change 2013: The Physical Science Basis. Contribution of Working Group I to the Fifth Assessment Report of the Intergovernmental Panel on Climate Change. Cambridge, and New York, Cambridge University Press, 2013. www.ghgprotocol.org/sites/default/files/ghgp/Global-Warming-Potential-Values \%20\%28Feb\%2016\%202016\%29_1.pdf Date last accessed: 7 January, 2020.

2 European Commission. Regulation (EU) No 517/2014 of the European Parliament and of the Council of 16 April 2014 on Fluorinated Greenhouse Gases and Repealing Regulation (EC) No 842/2006 Text with EEA Relevance. https://eur-lex.europa.eu/legal-content/EN/TXT/?uri=uriserv:OJ.L_.2014.150.01.0195.01.ENG Date last accessed: 7 January, 2020.

3 House of Commons Environmental Audit Committee. UK Progress on Reducing F-gas Emissions. 18 April, 2018. https://publications.parliament.uk/pa/cm201719/cmselect/cmenvaud/469/469.pdf. Date last accessed: 7 January, 2020.

4 Dekhuijzen PN, Lavorini F, Usmani OS. Patients' perspectives and preferences in the choice of inhalers: the case for Respimat $\left({ }^{\circ}\right)$ or HandiHaler $\left({ }^{\circ}\right)$. Patient Prefer Adherence 2016; 10: 1561-1572.

5 Lavorini F, Corrigan CJ, Barnes PJ, et al. Retail sales of inhalation devices in European countries: so much for a global policy. Respir Med 2011; 105: 1099-1103.

6 Usmani OS, Scullion J, Keeley D. Our planet or our patients-is the sky the limit for inhaler choice? Lancet Respir Med 2019; 7: 11-13.

7 Cates CJ, Welsh EJ, Rowe BH. Holding chambers (spacers) versus nebulisers for beta-agonist treatment of acute asthma. Cochrane Database Syst Rev 2013; CD000052.

8 van Geffen WH, Douma WR, Slebos DJ, et al. Bronchodilators delivered by nebuliser versus pMDI with spacer or DPI for exacerbations of COPD. Cochrane Database Syst Rev 2016; CD011826.

9 Keeley D, Partridge MR. Emergency MDI and spacer packs for asthma and COPD. Lancet Respir Med 2019; 7 ; 380-382.

10 Muraki M, Gose K, Hanada S, et al. Which inhaled corticosteroid and long-acting $\beta$-agonist combination is better in patients with moderate-to-severe asthma, a dry powder inhaler or a pressurized metered-dose inhaler? Drug Deliv 2017; 24: 1395-1400. 
11 Sanchis J, Gich I, Pedersen S. Systematic review of errors in inhaler use: has patient technique improved over time? Chest 2016; 150: 394-406.

12 Usmani OS, Lavorini F, Marshall J, et al. Critical inhaler errors in asthma and COPD: a systematic review of impact on health outcomes. Respir Res 2018; 19: 10.

13 Hanania NA, Wittman R, Kesten S, et al. Medical personnel's knowledge of and ability to use inhaling devices. Metered-dose inhalers, spacing chambers, and breath-actuated dry powder inhalers. Chest 1994; 105: 111-116.

14 Plaza V, Giner J, Rodrigo GJ, et al. Errors in the use of inhalers by health care professionals: a systematic review. J Allergy Clin Immunol Pract 2018; 6: 987-995.

15 Casset A, Meunier-Spitz M, Rebotier P, et al. Asthma management and inhalation techniques among community pharmacists in 2009: a comparison with the 1999 survey. J Asthma 2014; 51: 964-973.

16 Björnsdóttir US, Sigurðardóttir ST, Jonsson JS, et al. Impact of changes to reimbursement of fixed combinations of inhaled corticosteroids and long-acting $\beta_{2}$-agonists in obstructive lung diseases: a population-based, observational study. Int J Clin Pract 2014; 68: 812-819.

17 Keeley D. Large volume plastic spacers in asthma. BMJ 1992; 305: 598-599.

18 Price DB, Roman-Rodriguez M, McQueen RB, et al. Inhaler errors in the CRITIKAL study: type, frequency, and association with asthma outcomes. J Allergy Clin Immunol Pract 2017; 5: 1071-1081.

19 Usmani OS. Choosing the right inhaler for your asthma or COPD patient. Ther Clin Risk Manag 2019; 15: 461-472.

20 Asthma UK. UK Asthma Death Rates Among Worst in Europe. www.asthma.org.uk/about/media/news/ press-release-uk-asthma-death-rates-among-worst-in-europe/ Date last accessed: 7 January, 2020.

21 Levy ML. The national review of asthma deaths: what did we learn and what needs to change? Breathe (Sheff) 2015; 11: 14-24.

22 Asher I, Bissell K, Chiang CY, et al. Calling time on asthma deaths in tropical regions-how much longer must people wait for essential medicines? Lancet Respir Med 2019; 7: 13-15.

23 Sakaan S, Ulrich D, Luo J, et al. Inhaler use in hospitalized patients with chronic obstructive pulmonary disease or asthma: assessment of wasted doses. Hosp Pharm 2015; 50: 386-390.

24 Jeswani HK, Azapagic A. Life cycle environmental impacts of inhalers. J Cleaner Prod 2019; 237: 117733.

25 Chiesi Group. Chiesi Outlines €350 Million Investment and Announces First Carbon Minimal Pressurised Metered Dose Inhaler (pMDI) for Asthma and COPD www.chiesi.com/en/chiesi-outlines-350-million-investmentand-announces-first-carbon-minimal-pressurised-metered-dose-inhaler-pmdi-for-asthma-and-copd/ Date last accessed: 7 January, 2020.

26 National Institute for Health and Care Excellence (NICE). Patient Decision Aid Inhalers for Asthma. www.nice. org.uk/guidance/ng80/resources/inhalers-for-asthma-patient-decision-aid-pdf-6727144573 Date last accessed: 7 January, 2020. 